\title{
Graduate and Undergraduate Faculty Collaboration Utilizing Peer Observation to Enhance Educational Opportunities for Students and Faculty: A Case Example
}

\author{
Christopher E. Barton \\ Belmont University \\ Christi L. Williams \\ Belmont University \\ John S. Halle \\ Belmont University \\ Lori McGrew \\ Belmont University
}

\begin{abstract}
While evidence supports the use of cadavers to facilitate the teaching and learning of human anatomy, cadaver-based teaching may not be present at the undergraduate level at many institutions due to limited laboratory access, financial constraints, and the lack of qualified faculty trained to teach in this type of setting. The following case example outlines a unique program designed to provide cadaver-based instruction to undergraduate students, while simultaneously training undergraduate faculty to teach in this setting through peer observational methods. More specifically, the following teaching collaboration was designed with the intent to achieve the following: 1) expose undergraduate anatomy students to cadaver-based learning; 2) provide education and training to undergraduate faculty so they are better qualified to teach human anatomy in the context of a cadaver laboratory; 3) provide graduate physical therapy students additional opportunities to dissect and reinforce their anatomy knowledge; and 4) demonstrate the value of interdisciplinary collaboration. Eighty-one undergraduate students were exposed to the cadaver laboratory for four educational sessions throughout the semester. Course evaluations revealed that 93\% of the undergraduate students reported that their experiences in the cadaver laboratory served to enhance their learning, and 97\% reported that the use of human cadavers should be continued in future courses. This interdisciplinary collaboration allowed anatomy instruction to be expanded to previously unserved student groups as well as provided a mechanism for professional development of undergraduate anatomy faculty. This collaborative model may serve as a template to promote new program development to enhance faculty and student learning, while simultaneously encouraging interdisciplinary collaboration across the university.
\end{abstract}

Keywords: interdisciplinary, peer observation, pedagogy, anatomy, cadaver 


\section{Introduction}

The ultimate goal of an educator is to provide the best instruction in a way that engages students and provides them with the requisite knowledge and skills to be successful in their chosen endeavor. The challenge for educators is to teach with the most effective methodology, and to solve barriers that work against this purpose. To successfully do this, faculty must develop creative and collaborative teaching relationships, find cost-effective ways to operate laboratory space, and ensure that all academic faculty have the training and knowledge to operate in the necessary environment for an optimal teaching and learning experience.

The following is a description of a collaborative pedagogical model that was developed to address various challenges and barriers that exist when teaching human anatomy at the undergraduate level. The purpose of the following manuscript is to describe the collaborative model that was used to enhance a human anatomy course that engaged numerous faculty members across multiple departments and colleges at Belmont University by utilizing interdisciplinary peer observation and instruction. The goals of this case example are outlined below but it is important to note that the collaborative model described can also serve as a template for other disciplines to promote faculty development when adding a new program or when improving an existing program.

The goals of this interdisciplinary collaboration included the following:

1. Provide undergraduate students with the opportunity to learn in a cadaver-based laboratory setting, an optimal teaching practice supported by previously published reports (Aziz et al., 2002; Kerby, Shukur, \& Shalhoub, 2011; Ann R, 2007; Azer \& Eizenberg, 2007; Korf et al., 2008; Papa, Vaccarezza, \& Liston, 2013).

2. Provide opportunities for peer observation and professional development of undergraduate faculty members, as well as pedagogical training that would prepare them to teach in a cadaver-based laboratory environment

3. Provide invaluable opportunities for graduate students to have additional time dissecting in the human anatomy laboratory

4. Establish an anatomy "team" composed of faculty members spanning both the undergraduate and graduate levels

\section{Background}

\section{Peer observation}

Current trends in teaching at the college level include increased interdisciplinary collaboration and professional development (Sicat et al., 2014; Glowacki-Dudka \& Brown, 2007). Not only has there been evidence suggesting that interdisciplinary collaboration is beneficial for students (Jones, 2009), there is also evidence to suggest there are benefits for faculty members involved in these collaborative efforts (Sicat et al., 2014; Glowacki-Dudka \& Brown, 2007). For instance, faculty participation in an interdisciplinary peer observation experience can serve to increase one's pedagogical effectiveness, improve relationships by creating a sense of community among peers, and diminish the traditional silos that might exist between academic disciplines (Sicat et al., 2014; Glowacki-Dudka \& Brown, 2007; Bryk \& Driscoll, 1988). 
Keig and Waggoner suggested that while academic faculty often employ good pedagogical strategies in the classroom, there is always room for improvement in teaching and they argued that it is the role of faculty alone, to improve one's teaching effectiveness (Keig \& Waggoner, 1994). More specifically, the authors state that "In short, college teaching will improve when faculty support each other with expertise that is uniquely theirs, apart from what students, teaching consultants, and academic administrators can contribute to instructional improvement." (Keig \& Waggoner, 1994)

Peer observation occurs when faculty spend time observing their peers engage in the act of teaching with the ultimate goal of improving one's own pedagogical effectiveness (Hendry \& Oliver, 2012). Many institutions have used this process to provide their faculty with the opportunity to visualize and learn from colleagues' teaching, providing mutual benefit to all faculty involved (Hendry \& Oliver, 2012; Bennett \& Barp, 2008; Byrne, Brown, \& Challen, 2010). Previous studies have reported that college faculty found significant benefit from the act of watching others teach (Bell, 2001; Bell \& Mladenovic, 2008; Hendry \& Oliver, 2012).

\section{Cadaver-based human anatomy instruction}

One area in which interdisciplinary approaches to education and peer observation may be of importance is in teaching human anatomy at the undergraduate level. Having a strong foundation in human anatomy is critical to prepare students for careers in healthcare and other medicallyrelated fields. Unfortunately, over the last 30 years, the amount of time devoted to teaching anatomy in medical school curricula around the world has significantly declined (Shaffer, 2004; Craig, Tait, Boers, \& McAndrew, 2010; Drake, McBride, Lachman, \& Pawlina, 2009), thus stirring considerable debate of how and when to teach anatomy to students pursuing medical and other healthcare related degrees (Ann R, 2007; Bergman, Prince, Drukker, van der Vleuten, \& Scherpbier, 2008; Gogalniceanu, O’Connor, \& Raftery, 2009; Korf et al., 2008; Bergman, van der Vleuten, \& Scherpbier, 2011). This decrease in anatomy training in medical and graduate level curricula makes a critical point that anatomy at the undergraduate level is of significant importance, especially for those students pursuing further training in medically-focused programs (Papa \& Vaccarezza, 2013). Therefore it stands to reason that undergraduate students should be exposed to the best pedagogical practices in anatomy education an institution can offer.

While there are many pedagogical approaches to effectively teach human anatomy, multiple reports suggest that using cadavers to teach human anatomy is most beneficial (Kerby et al., 2011; Ann R, 2007; Azer \& Eizenberg, 2007; Korf et al., 2008; Saltarelli, Roseth, \& Saltarelli, 2014). The use of textbooks, lecture materials, plastic anatomical models, computer simulations, virtual dissections and other three-dimensional and digital teaching tools are common adjuncts to teaching anatomy, and while there are many benefits to using these teaching aides, (Chan \& Cheng, 2011; Brenton et al., 2007; Pereira et al., 2007; Peterson \& Mlynarczyk, 2016) evidence suggests that they cannot replace the value that is added when human cadavers are used to teach anatomy (Kerby et al., 2011; McNulty, Sonntag, \& Sinacore, 2009; Sugand, Abrahams, \& Khurana, 2010; Saltarelli et al., 2014; Chapman, Hakeem, Marangoni, \& Prasad, 2013).

Historically, human anatomy courses, especially at the undergraduate level, have been content driven courses. They tend to be loaded with facts, requiring significant memorization with little application and ultimately students gain little understanding of the relevance and application of the material (Johnson, Charchanti, \& Troupis, 2012; Patel \& Moxham, 2006). Evidence suggests that one benefit of cadaver-based anatomy courses is that it provides students with the

Journal of the Scholarship of Teaching and Learning, Vol. 18, No. 3, September 2018.

josotl.indiana.edu 
ability to analyze and apply the information they are learning (Miller, Perrotti, Silverthorn, Dalley, \& Rarey, 2002; Terrell, 2006; AAMC-HHMI., 2009). This type of active learning has been shown to be superior to memorization (Dangerfield, Bradley, \& Gibbs, 2000; Lujan \& DiCarlo, 2006) and promotes deeper learning (Ann R, 2007; Rolfe \& Sanson-Fisher, 2002; Dusseau, Knutson, \& Way, 2008; Krontiris-Litowitz, 2008). In a study by Azer and Eizenberg (2007), students agreed that dissection deepened their understanding of anatomical structures, provided them with a threedimensional perspective of the structures and helped them recall what they learned in class. Students also noted that they preferred this type of learning over any other approach to teaching anatomy (Azer \& Eizenberg, 2007; Chapman et al., 2013).

Despite the published benefits of using cadavers to teach anatomy, (Kerby et al., 2011; Ann R, 2007; Azer \& Eizenberg, 2007; Korf et al., 2008; Saltarelli et al., 2014) many professional healthcare workers, including nurses, do not have the opportunity to learn human anatomy in a cadaver-based environment (Johnston, 2010). Given this information, combined with the fact that there is a decline in the amount of anatomy education in the medical school curriculum, (Shaffer, 2004; Craig et al., 2010; Drake et al., 2009) an even stronger case can be made for providing high quality human anatomy education at the undergraduate level, and utilizing cadaver-based teaching practices when possible (Ann R, 2007; Bergman et al., 2008; Gogalniceanu et al., 2009; Korf et al., 2008; Bergman et al., 2011).

The challenge in providing cadaver-based anatomy courses at the undergraduate level is that not all institutions, especially those institutions that do not have a medical program on campus, have access to the appropriate facilities or laboratory space specific for cadaver-based instruction (McLachlan \& Patten, 2006). Another common barrier to integrating this teaching methodology is the cost associated with cadaver use. The current mean cost to purchase a cadaver in the United States is approximately $\$ 2,000.00$ per cadaver (Simpson, 2014). Furthermore, there are additional costs associated with delivery, maintenance of the laboratory space, proper biohazard disposal, cremation fees, various tools to properly preserve and dissect the cadavers, dissection manuals, and anatomy texts (Simpson, 2014). Finally, trained faculty to teach cadaver-based anatomy is a limiting factor given that there is a shortage of qualified faculty to teach human anatomy using cadavers at both the undergraduate and graduate levels (Ann R, 2007). Faculty members who were taught using prosected (previously dissected) cadavers, or who have not had prior cadaver-based training, do not have the requisite skills to perform the actual dissection. In addition, they lack the knowledge of the process of ordering, prepping, cleaning and maintaining the cadavers and the facility, as well as the rules associated with the otherwise restricted laboratory space and the Anatomical (Whole Body) Donation Program.

Challenges such as those outlined above may also provide unique opportunities to grow faculty, students and various academic programs on college campuses. The following describes how the above challenges were addressed through collaboration across disciplines and by engaging in peer-observational instruction to expand upon an undergraduate human anatomy course at Belmont University.

\section{Methodology}

Belmont University, located in Nashville, Tennessee, is predominantly an undergraduate liberal arts school with a student population of approximately 7,350. The Department of Biology (DoB, College of Sciences and Mathematics) offers a Bachelor of Science degree in Biology and currently has approximately 160 students within the department. Each semester the DoB offers six

Journal of the Scholarship of Teaching and Learning, Vol. 18, No. 3, September 2018.

josotl.indiana.edu 
to eight sections of human anatomy and physiology, comprised of students majoring in Exercise Science, Nursing, Psychology, Chemistry, as well as other areas. In addition to the undergraduate population, there are five doctoral level programs at Belmont University, three of which are in the College of Health Sciences, and include Nursing, Occupational Therapy and Physical Therapy.

Belmont University added a human anatomy laboratory on campus, primarily for use by the Doctorate of Physical Therapy (DPT) Program, which at the time was utilizing laboratory space at another university. Students in the DPT program complete a human anatomy course which includes six hours/week in the human anatomy laboratory, in which they perform full-body dissections in groups of four to five per human cadaver. The Doctorate of Occupational Therapy (OTD) students utilize the laboratory for two hours/week to review the prosected (previously dissected) cadavers once the dissections are completed by the DPT students.

Due to the human anatomy laboratory not being used year round, it was felt to be a resource that could impact other groups educationally. Therefore DPT and OTD faculty collaborated with undergraduate DoB faculty to expand cadaver-based instruction to undergraduate students enrolled in human anatomy and physiology. This would offer students who are pursuing undergraduate degrees in fields of study such as Exercise Science, Nursing, Pre-Medical, Pre-Physical Therapy, Pre-Occupational Therapy, as well as others an opportunity to learn in a cadaver-based environment. This type of anatomy instruction had not previously been part of the undergraduate curriculum at Belmont University and therefore the following case example outlines the methodology behind the interdisciplinary collaboration and peer observational methods used to accomplish the above goals.

\section{Addressing Barriers to Cadaver-Based Teaching}

Offering cadaver based courses does not come without a significant cost, therefore creative collaborative efforts were needed to maximize the use of each cadaver and drive-down the perstudent cost of utilization of the anatomy laboratory by incorporating more programs across multiple departments. For instance, following the fall semester when the DPT and OTD students had completed their coursework, three cadavers were retained for undergraduate use during the spring semester. This allowed the undergraduate program to have access to four total cadavers, while only being responsible for the purchase and dissection of one new cadaver.

Since the undergraduate faculty members at Belmont University had not previously been trained in a cadaver-based laboratory environment, there remained a need to provide instruction to these faculty members regarding how to purchase, dissect and maintain the cadavers and laboratory space. By teaming up with graduate faculty members experienced in these processes, undergraduate faculty members were educated on the Anatomical (Whole Body) Donation program, and exposed to all activities required to utilize the laboratory space and care for the cadavers. In addition, since undergraduate students would not be performing full dissections as part of their coursework and undergraduate faculty did not have prior experience dissecting cadavers, there also remained a need to provide further training to these instructors on how to dissect the newly purchased cadaver. Due to the meticulous skill required to perform dissections it was not reasonable to provide training to undergraduate faculty for this process as it would have required considerable time outside of scheduled classes for both graduate and undergraduate faculty members, or a significant cost associated with purchasing outside educational instruction for undergraduate faculty. To address this problem in a cost-effective and time-effective manner, first-year DPT students who completed full dissections the preceding semester were offered the

Journal of the Scholarship of Teaching and Learning, Vol. 18, No. 3, September 2018.

josotl.indiana.edu 
opportunity to volunteer to complete the additional cadaver dissection for undergraduate use. While no extra credit was offered and all activity was to be performed outside of normal class time, six DPT students elected to perform this dissection because they believed the experience would grant them an additional learning opportunity that would result in further retention of past and current course information.

The remaining education needed by undergraduate faculty was the hands-on experience of identifying structures on various cadavers and recognizing different tissue types and variations that exist across specimens. This was addressed through peer observational teaching and learning collaboration between graduate faculty and undergraduate faculty, in which the graduate faculty members performed teaching sessions that were one hour in length to the undergraduate students while undergraduate faculty members observed. There were four sections of undergraduate anatomy students (24 students per section), so to provide an optimal student to faculty ratio, each section was divided in half so there were approximately 12 students per laboratory session (Figure 1). Figure 1 demonstrates how this division of the laboratory sections resulted in the same onehour teaching session being provided eight different times. The first six sessions were provided by one of the four participating graduate faculty members from either the DPT or OTD program, and the last two sessions were provided by the undergraduate faculty member responsible for teaching that lab section while a graduate faculty member observed their teaching methods and was available to provide feedback and assistance as needed (Figure 1 and Table 1). It is important to note that graduate faculty members voluntarily provided this instruction outside of their normal class time. Each graduate faculty member volunteered a total of approximately six hours throughout the semester for teaching the undergraduate students. Undergraduate faculty were present during all teaching sessions that were taught by graduate faculty members which provided them with approximately 18 hours of peer-observational training, all of which occurred during normal lab time for the undergraduate faculty members and at no additional cost for the university.

Since there were four different graduate faculty members involved in this collaboration, it exposed undergraduate faculty members and students to a range of teaching styles, a variety of differing emphases across the professional disciplines, and clinical implications taught from a healthcare perspective. Given that the undergraduate faculty were not healthcare professionals, their ability to observe graduate faculty in this setting provided them with a valuable knowledge base that increased their ability to engage their students in the "application" of anatomical concepts. The use of peer observation modeled here has been shown to be effective in promoting faculty development and teaching effectiveness (Bell, 2001; Bell \& Mladenovic, 2008; Hendry \& Oliver, 2012).

With the plethora of literature supporting peer observation as a mode of faculty professional development and growth (Hendry \& Oliver, 2012; Bennett \& Barp, 2008; Byrne et al., 2010) this peer observation experience provided the opportunity for undergraduate faculty to acquire additional anatomy knowledge, undergraduate students to be exposed to a cadaver-based learning environment, graduate DPT students to gain additional dissection experience and all faculty to gain a sense of community across multiple departments, colleges, and graduate/undergraduate programs; a win-win situation for everyone involved.

Journal of the Scholarship of Teaching and Learning, Vol. 18, No. 3, September 2018.

josotl.indiana.edu 

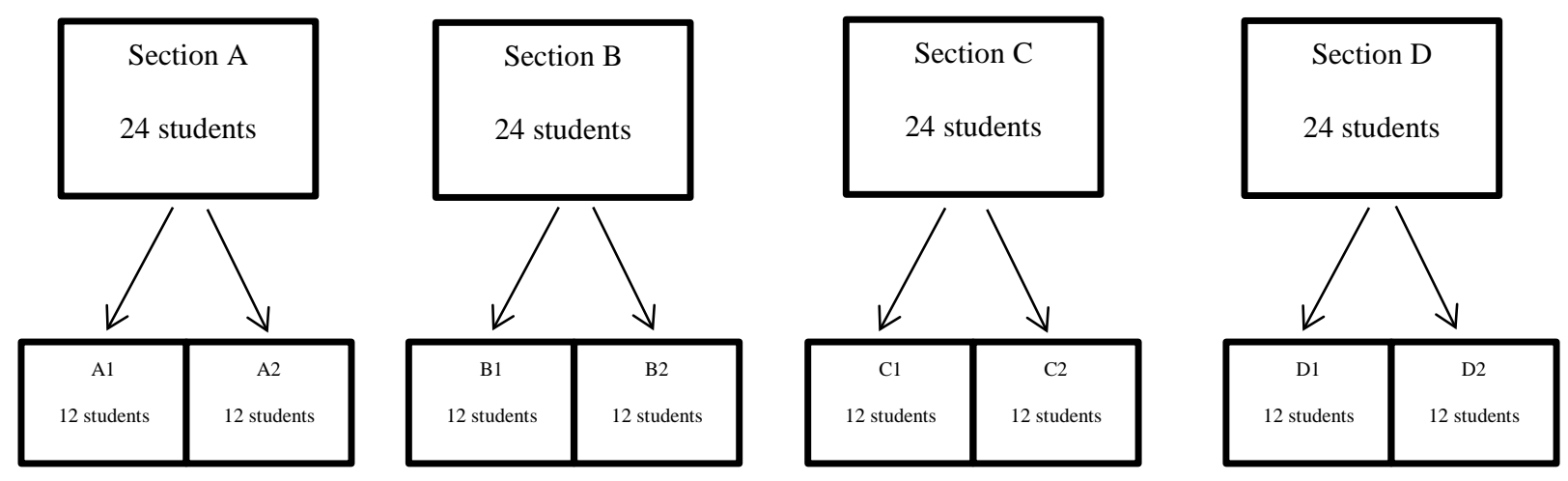

Topic: Shoulder Girdle / Upper Extremity

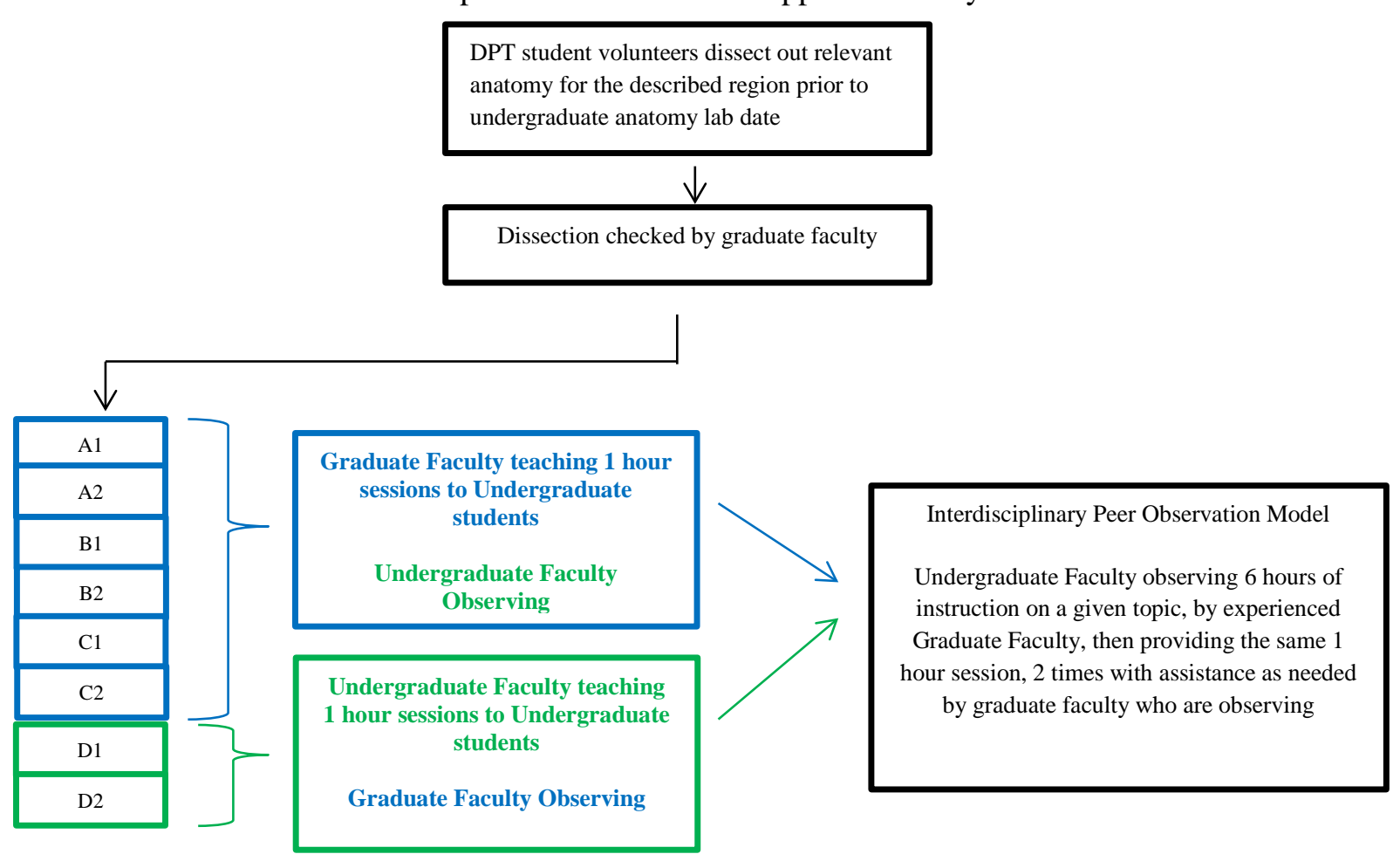

Figure 1. Organizational model for teaching instruction. The described model was designed by undergraduate and graduate faculty at Belmont University and outlines the methods used by DPT and OTD faculty and DPT students to provide an opportunity for both undergraduate student learning and professional development of undergraduate anatomy faculty.

Journal of the Scholarship of Teaching and Learning, Vol. 18, No. 3, September 2018.

josotl.indiana.edu 
Table 1. Gross anatomy orientation and teaching schedule for undergraduate anatomy and physiology courses

\begin{tabular}{|c|c|c|c|c|}
\hline Group & Time & Instructor & Purpose & Other Notes \\
\hline $\mathrm{A}$ & 0.5 hours & Graduate Faculty & Willed Donor Program Orientation & \\
\hline B & 0.5 hours & Graduate Faculty & Willed Donor Program Orientation & \\
\hline $\mathrm{C}$ & 0.5 hours & Graduate Faculty & Willed Donor Program Orientation & \\
\hline $\mathrm{D}$ & 0.5 hours & Graduate Faculty & Willed Donor Program Orientation & \\
\hline A-1 & 1 hour & Graduate Faculty & $\begin{array}{c}\text { Shoulder Girdle \& Upper } \\
\text { Extremity } \\
\text { Shoulder Girdle \& Upper }\end{array}$ & UG Faculty Observing \\
\hline A-2 & 1 hour & Graduate Faculty & $\begin{array}{c}\text { Extremity } \\
\text { Shoulder Girdle \& Upper }\end{array}$ & UG Faculty Observing \\
\hline B-1 & 1 hour & Graduate Faculty & $\begin{array}{l}\text { Extremity } \\
\text { Shoulder Girdle \& Upper }\end{array}$ & UG Faculty Observing \\
\hline B-2 & 1 hour & Graduate Faculty & $\begin{array}{l}\text { Extremity } \\
\text { Shoulder Girdle \& Upper }\end{array}$ & UG Faculty Observing \\
\hline $\mathrm{C}-1$ & 1 hour & Graduate Faculty & $\begin{array}{c}\text { Extremity } \\
\text { Shoulder Girdle \& Upper }\end{array}$ & UG Faculty Observing \\
\hline $\mathrm{C}-2$ & 1 hour & Graduate Faculty & $\begin{array}{l}\text { Extremity } \\
\text { Shoulder Girdle \& Upper }\end{array}$ & UG Faculty Observing \\
\hline D-1 & 1 hour & UG Faculty & $\begin{array}{l}\text { Extremity } \\
\text { Shoulder Girdle \& Upper }\end{array}$ & Graduate Faculty Observing \\
\hline D-2 & 1 hour & UG Faculty & Extremity & Graduate Faculty Observing \\
\hline A-1 & 1 hour & Graduate Faculty & Pelvic Girdle and Lower Extremity & UG Faculty Observing \\
\hline A-2 & 1 hour & Graduate Faculty & Pelvic Girdle and Lower Extremity & UG Faculty Observing \\
\hline B-1 & 1 hour & Graduate Faculty & Pelvic Girdle and Lower Extremity & UG Faculty Observing \\
\hline B-2 & 1 hour & Graduate Faculty & Pelvic Girdle and Lower Extremity & UG Faculty Observing \\
\hline $\mathrm{C}-1$ & 1 hour & Graduate Faculty & Pelvic Girdle and Lower Extremity & UG Faculty Observing \\
\hline $\mathrm{C}-2$ & 1 hour & Graduate Faculty & Pelvic Girdle and Lower Extremity & UG Faculty Observing \\
\hline D-1 & 1 hour & UG Faculty & Pelvic Girdle and Lower Extremity & Graduate Faculty Observing \\
\hline D-2 & 1 hour & UG Faculty & Pelvic Girdle and Lower Extremity & Graduate Faculty Observing \\
\hline A-1 & 1 hour & Graduate Faculty & Head, Neck and Trunk & UG Faculty Observing \\
\hline A-2 & 1 hour & Graduate Faculty & Head, Neck and Trunk & UG Faculty Observing \\
\hline B-1 & 1 hour & Graduate Faculty & Head, Neck and Trunk & UG Faculty Observing \\
\hline B-2 & 1 hour & Graduate Faculty & Head, Neck and Trunk & UG Faculty Observing \\
\hline $\mathrm{C}-1$ & 1 hour & Graduate Faculty & Head, Neck and Trunk & UG Faculty Observing \\
\hline $\mathrm{C}-2$ & 1 hour & Graduate Faculty & Head, Neck and Trunk & UG Faculty Observing \\
\hline D-1 & 1 hour & UG Faculty & Head, Neck and Trunk & Graduate Faculty Observing \\
\hline D-2 & 1 hour & UG Faculty & Head, Neck and Trunk & Graduate Faculty Observing \\
\hline
\end{tabular}

\section{Findings}

\section{Outcomes of Collaborative Model}

Anonymous course assessment surveys were provided to all undergraduate and graduate students to obtain information regarding their perception of this cadaver laboratory experience. Surveys utilized a Likert type scale with responses from 1 to 5, with a 5 representing 'strongly agree' and a 1 representing 'strongly disagree'. Each survey also had open-ended questions that allowed the 
student to provide clear and honest responses. To minimize bias, both sets of surveys were given at the end of the semester when the students knew they could be honest and forthright in their responses. The collection of data was verified by the Belmont University Institutional Review Board as exempt according to 45CFR46.101(b)(1).

Undergraduate students were provided a survey with nine Likert-based questions, and five open-ended questions (Appendix A). Graduate students were provided a survey with 10 Likertbased questions and 15 open-ended questions (Appendix B). For all Likert-based questions, data were compiled in two ways. First, the mean of responses from the Likert-scale were calculated to compile an average response from the entire cohort. Second, the percentage of "positive responses," or the percentage of students choosing "agree” or "strongly agree” was also calculated and reported (see Figures 2 and 3). The responses from the open-ended, qualitative questions were used to identify recurring trends from student surveys.

\section{Undergraduate Student Reported Outcomes}

Eighty-one undergraduate students were exposed to this model of learning. From this total, 61 students submitted responses for a response rate of $74.4 \%$. The demographic information regarding sex, major, and prior exposure to a cadaver lab are displayed in Table 2. The majority of undergraduate students were freshmen (77\%), majoring in nursing (85.3\%), and nearly $87 \%$ of these undergraduate students reported that they did not have any prior exposure to a cadaver-based laboratory setting.

In examining the student responses to the laboratory sessions, the results were overwhelmingly positive. Ninety-three percent of students felt that their experiences in the human anatomy laboratory served to enhance their learning within the course, and $94 \%$ of the students responded that the human anatomy laboratory visits integrated well into the overall course design (Figure 2). Ninety-seven percent of undergraduate students reported that the use of human cadavers should be continued in future anatomy and physiology courses, and $87 \%$ of students stated that the use of human cadavers is actually required to most effectively learn human anatomy (Figure 2). 
Table 2. Demographic information and prior laboratory experience of undergraduate students enrolled in anatomy and physiology courses

\begin{tabular}{lc}
\hline Undergraduate Classification & N (\% Total) \\
\hline Freshman & $47(77 \%)$ \\
Sophomore & $6(9.8 \%)$ \\
Junior & $3(4.9 \%)$ \\
Senior & $5(8.2 \%)$ \\
& \\
\hline Major & \\
\hline Nursing & $51(83.6 \%)$ \\
Music Therapy & $3(4.9 \%)$ \\
Exercise Science & $3(4.9 \%)$ \\
Pharmaceutical Studies & $1(1.6 \%)$ \\
Biology & $1(1.6 \%)$ \\
Neuroscience & $1(1.6 \%)$ \\
& \\
\hline Prior Exposure to Cadaver Laboratory? & \\
\hline No & $53(86.9)$ \\
Yes & $8(13.1)$
\end{tabular}

To be certain that students were taking the time to read each question carefully, one question was worded to solicit a negative response if students perceived cadaver-based learning to be a positive experience (top question, Figure 2). Student responses to this question again affirmed the benefits of cadaver-based instruction, and overall the undergraduate student responses supported the use of cadaver-based instruction over the traditional method of teaching with models and computer aided instruction (Figure 2). These data are in agreement with student-reported outcomes in previous studies (Johnston, 2010; Böckers et al., 2010; Chapman et al., 2013).

As mentioned earlier, undergraduate student surveys also included five open-ended questions about their perceptions related to having the opportunity to learn in a cadaver-based laboratory. Perhaps the most commonly-reported benefit was that learning from human cadavers provided them with an improved understanding of human anatomy (Table 3). Furthermore, students reported that the learning that occurred in this setting was an improvement over the use of different anatomical models, textbook images, and/or lectures, and students also reported that they felt that the use of cadavers increased information retention in the course (Table 3).

Regarding working with cadavers, one student commented that "Seeing things in the cadavers is different than looking at a picture in a textbook or a plastic model. It really makes you realize how complex and fascinating and REAL the human body is." Another student stated that "I thought it was extremely helpful to be able to see exactly how the muscles and bones we had been studying were actually organized in a real human's body. They look so different from the models, and it was really cool to be able to compare the real ones to the pictures on our study guides." From these comments, it is clear that students not only found this experience beneficial in regards to learning, but they also had a sense of enthusiasm and excitement about learning in this way. 


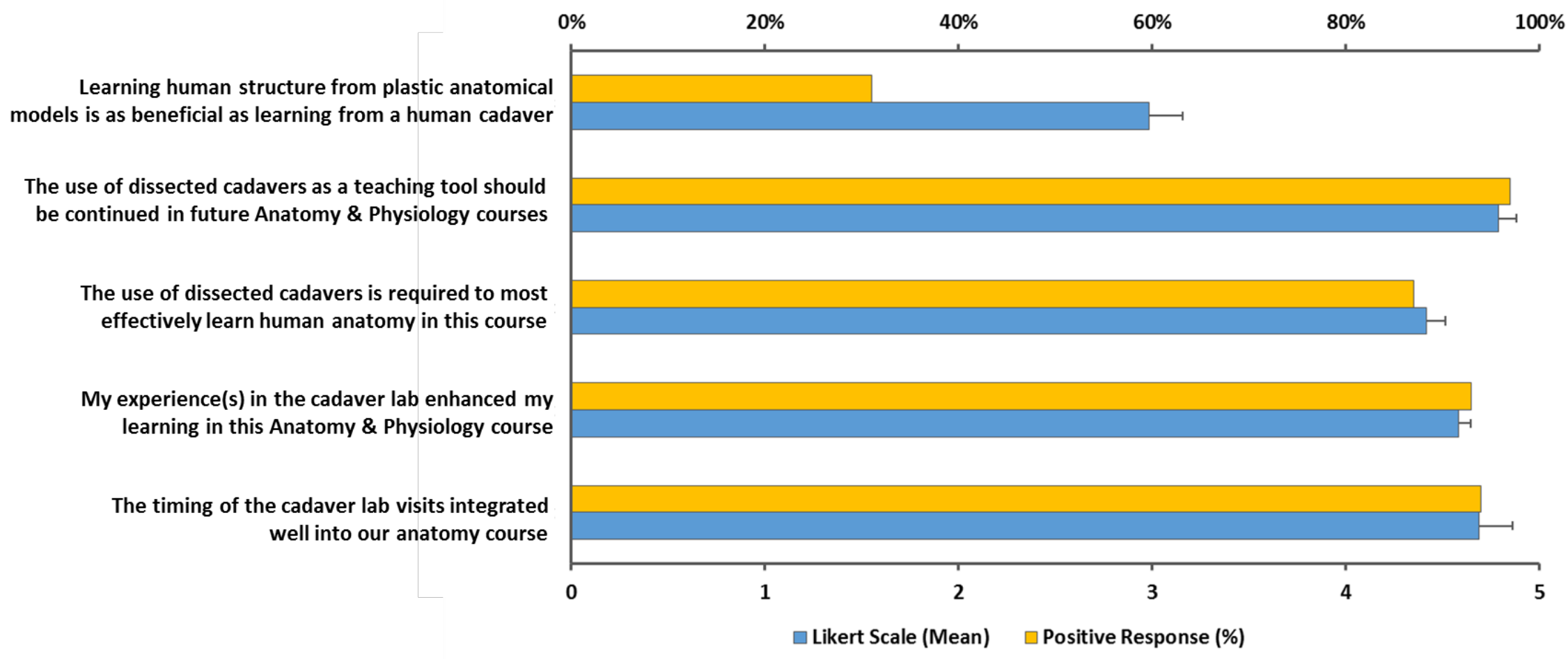

Figure 2. Undergraduate Student Survey Response. Undergraduate students rated their experiences using a five-point Likert scale, where 1 = strongly disagree and $5=$ strongly agree. Data were compiled and are presented as the mean (blue bars) for Likert scale questions with standard error being shown. Additionally, positive response (orange bars) is accounting for the total number of students selecting agree (4) or strongly agree (5) for each statement. 
Table 3. Outcomes reported by undergraduate students from a cadaver-based learning experience* $^{*}$

Improved understanding of anatomical organization

Increased learning over anatomical models, textbooks, and/or lectures

Greater appreciation for the human body

Recognize and appreciate inter-individual anatomical differences

Increased retention of information learned in the classroom setting

Better understanding of anatomical layers

Gained confidence studying within a cadaver laboratory

${ }^{*}$ Reported outcomes are not comprehensive, but represent recurring themes identified from self-reported student surveys

Perhaps an unsurprising, yet well-received, outcome was the reported "greater appreciation for the human body" - one might argue that this level of appreciation can only be fully gained by having the opportunity to observe anatomical structures in this particular environment. One student commented that "seeing the muscles as they appear in real life was very interesting and helped me to understand their orientation and functions better than I did when studying the models. It gave me a new sense of respect for the human body. While it was a new and sometimes uncomfortable experience to see a human cadaver, I consider myself lucky to have had such an amazing learning experience, especially this early in my education." Taken collectively, the responses outlined in Figure 2 and Table 3 suggest that students perceived the use of human cadavers to greatly enhance their learning in this particular course.

Other notable responses were related to how this experience caused students to reflect upon their career plans. For example, following her experience in the lab, one student realized that " $I$ know now that I don't necessarily want to be a surgical nurse." For another student, she found that she is now "considering becoming a surgical nurse because the organs and the human body really intrigued me." It is important to note that experiences such as these can have a significant impact on the perceived career goals of undergraduate students. Without such an experience, it is possible that some students may not come to these realizations until much later in their educational or healthcare careers.

\section{Undergraduate Faculty Outcomes}

At Belmont University, the interdisciplinary model described here allowed the undergraduate faculty members to spend a significant amount of time participating in peer observation of graduate faculty as they taught undergraduate students in a cadaver-based environment. As previously noted, peer observation is a pedagogical tool allowing faculty to engage in interdisciplinary collaborations that promote faculty development and pedagogical effectiveness (Hendry \& Oliver, 2012; Bennett \& Barp, 2008; Byrne et al., 2010). Following this observation period, undergraduate faculty then took on the responsibility of teaching the same information under the direct observation and review of a graduate faculty member.

As a result of this collaborative experience, undergraduate faculty members gained an ability to teach independently using human cadavers. In addition, they were exposed to multiple pedagogical styles from their observations of four different graduate faculty members. This Journal of the Scholarship of Teaching and Learning, Vol. 18, No. 3, September 2018. josotl.indiana.edu 
experience provided a myriad of clinical applications that can only be gained from having a personal, first-hand experience with highly trained anatomists and clinicians - an experience that many undergraduate anatomy faculty members have never had.

\section{Graduate Student Survey Responses}

Six DPT students, currently enrolled in their first year of physical therapy school participated by performing the necessary dissections on the one cadaver that was not retained from the prior semester. Five of the six students completed a survey about their dissection experience. As was the case with the undergraduate students, these volunteers felt positive about the experience, with every graduate student response indicating that they "strongly agreed," or "agreed" that they would be willing to volunteer for this experience again and all graduate students "strongly agreed" that they would recommend this opportunity to incoming DPT students (Figure 3).

Of these graduate volunteers, three of the five students who completed the survey stated that they also had access to a cadaver laboratory as an undergraduate student, and indicated that they felt they were more prepared than many of their peers at the start of the DPT program due to this prior exposure. Forester et al. (2002) noted similar findings when comparing anatomy course outcomes in a medical school program between students who had a cadaver-based course as an undergraduate student and those who did not, and found interesting results in that those students with premedical gross anatomy $(n=236)$ earned significantly more points in the corresponding medical school course than students without the premedical coursework $(\mathrm{P}<0.05)$ (Forester, McWhorter, \& Cole, 2002). Additionally, every graduate student responding indicated that they believe it is highly beneficial for undergraduate students and healthcare majors to have exposure to such a setting.

Graduate DPT students also indicated that they felt fully prepared to independently complete the required cadaver dissections and felt strongly that the additional experience in the cadaver lab, and the time that it required, was beneficial to their learning and retention of human anatomy (Figure 3). All graduate students reported that having this additional time in the human anatomy laboratory helped them to better understand information that they were concomitantly learning in their kinesiology course, demonstrating that the perceived educational benefits gained from this collaborative model were not strictly limited to undergraduate students, but also extended to the participating graduate students.

Similar to the undergraduate student surveys, the graduate students were also provided with a number of open-ended questions. When asked why they were interested in volunteering for this experience, one student stated that "I volunteered because I believe there is no better way to learn anatomy." Another student reported that "I decided to volunteer for this opportunity to reinforce what was learned in the fall, and because this sort of hands on experience makes a huge difference for visual and kinesthetic learners." Additionally, these students felt strongly that having this volunteer dissection experience was critical for their understanding of courses they were simultaneously enrolled in, supporting the idea that the benefits gained through this teaching model were not limited to the undergraduate students. When asked if the additional dissection experience enhanced their understanding of their current coursework, one student responded that "It was very beneficial. It definitely helped in kinesiology because seeing the orientation of the muscles and how they inserted helped clarify why we (did) manual muscle testing and goniometry."

Journal of the Scholarship of Teaching and Learning, Vol. 18, No. 3, September 2018.

josotl.indiana.edu 


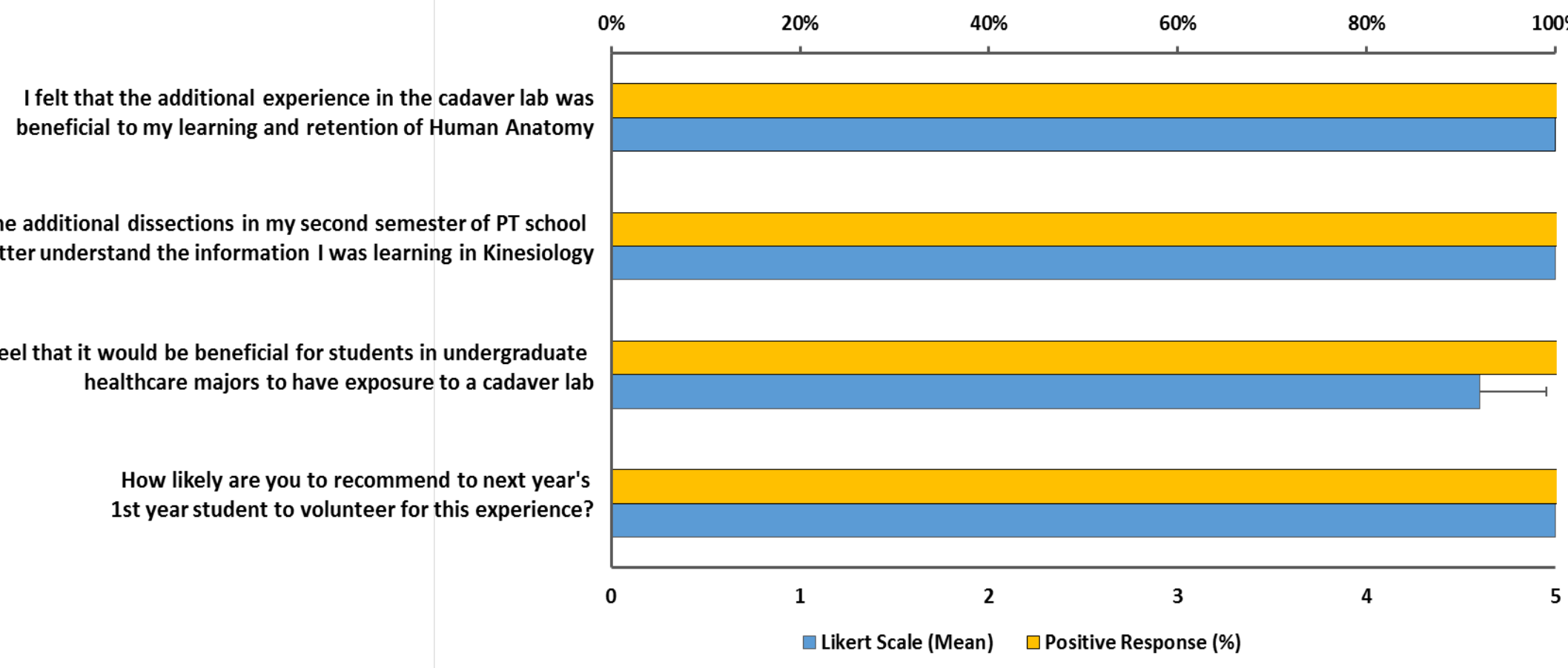

Figure 3. Graduate student survey response. Graduate students rated their experiences using a five-point Likert scale, where 1 = strongly disagree and 5 = strongly agree. Data were compiled and are presented as the mean (blue bars) for Likert scale questions with standard error being shown. Additionally, positive response (orange bars) is accounting for the total number of students selecting agree (4) or strongly agree (5) for each statement. 


\section{Graduate Faculty Outcomes}

While there was no formal compensation provided for the graduate faculty members who participated in the training of undergraduate faculty, there were several long-term benefits of this interdisciplinary collaboration for those involved. For instance, in addition to university scholarship opportunities, an 'anatomy team' developed as a result of training additional faculty members across departments to teach in the cadaver laboratory. By having a team of faculty with varied experience levels working collaboratively, the issue of a shortage in faculty members trained in a cadaver-laboratory setting was addressed, providing better usage of the laboratory space, and overall maintenance of the laboratory environment.

\section{Potential Benefits of this Collaboration for Belmont University}

While collaborative development of undergraduate faculty and exposing undergraduate students to cadaver-based learning were the driving forces behind the initiation of this collaboration, there were several other positive outcomes that surfaced. For instance, in working with undergraduate students, graduate faculty members were able share their expansive clinical knowledge with students and faculty from other departments. This allowed different disciplines to share their strengths, and it allowed a team of faculty to develop that were not functioning in a silo, but rather were working collaboratively across multiple disciplines and multiple colleges within a given institution. These interactions can serve to introduce undergraduate students to a new and exciting field, or alternatively may help students reflect upon the professional path that they envisioned and help assist some students in making a decision related to their future career that they would otherwise delay until in a graduate or professional program.

Both undergraduate and graduate students involved in this collaboration reported that they felt strongly that colleges and universities should make the effort to expose undergraduate science students to cadaver-based instruction. When limited to plastic models and textbooks, it is the application of information that is most easily lost in these undergraduate courses. For those students continuing on to medical school, physical therapy education, or some other healthcare training program, this exposure will provide them with a strong foundational base for their future education. This was shown to be the case in a previous study (C. A. Peterson \& Tucker, 2005) in which the investigators found that students who took anatomy as an undergraduate scored statistically more points in medical anatomy, and that taking a prosection-based anatomy laboratory as an undergraduate student improved performance in medical anatomy significantly. They concluded that experience in undergraduate human gross anatomy and anatomy laboratory courses are correlated with class rank in medical anatomy (Peterson \& Tucker, 2005).

Given this information, another potential benefit of this collaborative effort is that by offering cadaver-based learning at the undergraduate level, it may create an opportunity for the university to market to, and retain promising students wishing to pursue degrees in healthcarebased sciences. Therefore it would be reasonable in today's competitive college environment for institutions that have taken on the cost and effort to maintain an anatomy laboratory, to advertise this learning experience to demonstrate a 'value-added' advantage in today's university marketplace.

Another potential benefit to the university is that the increased collaboration across disciplines resulted in providing undergraduate faculty members with new and exciting methods of teaching their students at no outside cost. In addition, the ability of several colleges to share

Journal of the Scholarship of Teaching and Learning, Vol. 18, No. 3, September 2018.

josotl.indiana.edu 
budget resources, and the increased use of the laboratory space, all act to increase the efficiency of the lab and provide for a stronger fiscal defense of its continued use.

\section{Suggestions for improvement and follow-up analyses}

There are several suggestions for future development in this area. One recommendation would be to integrate a program such as this one in a way that allows for better assessment outcomes, such as tracking the grades of undergraduate students who are exposed/not exposed to cadaver-based learning to assess the overall performance outcomes of these students. It would also be helpful to provide a similar course assessment survey to undergraduate students who do not have access to cadaver-based learning to compare the students' perceptions to those who did participate in cadaver-based learning. Further, we believe that there may be merit in providing some type of assessment of anatomical knowledge to undergraduate faculty following a collaborative experience such as this.

\section{Conclusion}

In conclusion, after extending cadaver-based learning to the undergraduate level at Belmont University, the authors agree that when possible, this should be the pedagogy used to teach this discipline at both the undergraduate and graduate school level. The key point is that the interdisciplinary peer observation model described here was a beneficial way to offer a new teaching and learning opportunity at the undergraduate level, was done so in a very cost-effective manner for the university, and can be easily transferred to any institution that has access to a human anatomy laboratory. More importantly, this interdisciplinary peer observation collaboration can serve as a model for development of new programs or enhancement of current programs in any applicable area of academic study.

\section{Acknowledgements}

We would like to thank Dr. Kathy Galloway and Dr. Emmy Dagnan for assisting graduate students with dissections, providing teaching sessions to undergraduate anatomy students, and training of undergraduate faculty. We would also like to thank Dr. Renee Brown and Dr. Jennifer Thomas for their critical reading of the manuscript.

\section{Authors’ Note}

The authors of this article contributed equally to this work. 


\section{Appendix}

\section{Appendix 1. Undergraduate Student Experience Assessment Survey}

Please answer the following questions to the best of your ability:

1. What is your undergraduate classification?

2. What is your undergraduate major?

3. Please briefly describe your career goals.

4. Prior to this experience, have you ever learned in a cadaver-based environment?

\begin{tabular}{ccccc}
\multicolumn{4}{c}{ Please circle the best response to the questions below, using the following scale: } \\
1 & 2 & 3 & 4 & 5 \\
Strongly & Disagree & Neutral & Agree & Strongly Agree \\
Disagree & & & &
\end{tabular}

1. I felt comfortable during my time in the cadaver laboratory.
1
2
3
4
5

2. The teaching sessions in the cadaver laboratory were well organized.
1
2
3
4
5

3. The instructors leading sessions in the cadaver laboratory were knowledgeable in the subject matter being taught.
1
2
3
4
5

4. The instructors leading sessions in the cadaver laboratory communicated effectively when teaching.
1
2
3
4
5

5. My experience(s) in the cadaver laboratory enhanced my learning in this Anatomy \& Physiology course.

$\begin{array}{lllll}1 & 2 & 3 & 4 & 5\end{array}$

6. The use of dissected cadavers is required to most effectively learn human anatomy in this course.
1
2
3
4
5

7. Learning human anatomy from a plastic anatomical model is as beneficial as learning from dissected human cadavers.
1
2
3
4
5

8. The use of dissected human cadavers should be continued in future undergraduate Anatomy \& Physiology courses.
1
2
3
4
5

9. The timing of the cadaver lab visits integrated well into our anatomy course.
1
2
3
4

5

Qualitative Questions:

1. Describe any benefits that you experienced from learning in a cadaver laboratory setting.

2. Describe any aspects of the cadaver laboratory experience that you feel could be improved upon, or changed, in future Anatomy \& Physiology courses.

3. Please describe why you feel the use of dissected cadavers should, or should not, be included in future undergraduate Anatomy \& Physiology courses.

4. Describe you initial feelings towards learning in a cadaver laboratory and how, if at all, those feelings changed throughout the course of the semester.

Journal of the Scholarship of Teaching and Learning, Vol. 18, No. 3, September 2018.

josotl.indiana.edu 
5. Describe how, if at all, your cadaver laboratory experiences in this course have influenced your career plans.

\section{Appendix 2. Graduate Student Experience Assessment Survey}

\begin{tabular}{lcccc}
\multicolumn{2}{c}{ Please circle the best response to the questions below, using the following scale: } \\
1 & 2 & 3 & 4 & 5 \\
Strongly & Disagree & Neutral & Agree & Strongly Agree \\
Disagree & & & &
\end{tabular}

1. I felt that the additional experience in the cadaver lab was beneficial to my learning and retention of Human Anatomy

$\begin{array}{lllll}1 & 3 & 4 & 5\end{array}$

2. I had an appropriate amount of time to complete each dissection

$\begin{array}{lllll}1 & 2 & 3 & 5\end{array}$

3. I had a clear understanding of what structures were necessary to dissect for the Undergraduate Anatomy course
1
2
3
4
5

4. I felt that the additional dissections in my second semester of PT school helped me to better understand the information I was learning in Kinesiology
1
2
3
4
5

5. I felt very prepared to perform the dissections following my experience in the lab last semester
1
2
3
4
5

6. There was an appropriate number of students participating in the dissections
1
2
3
4
5

7. I feel that it would be beneficial for students in undergraduate healthcare majors to have exposure to a cadaver lab
1
2
3
4
5

8. The amount of time I spent prepping and performing the dissection was well worth the experience
1 2
3
4
5

9. How likely are you to volunteer for this experience again?

$\begin{array}{ccccc}1 & 2 & 3 & 4 & 5 \\ \text { Very unlikely } & \text { Unlikely } & \text { Neutral } & \text { Likely } & \text { Very Likely }\end{array}$

10. How likely are you to recommend that to next year's $1^{\text {st }}$ year students to volunteer for this experience?

$\begin{array}{ccccc}1 & 2 & 3 & 4 & 5 \\ \text { Very unlikely } & \text { Unlikely } & \text { Neutral } & \text { Likely } & \text { Very Likely }\end{array}$

Qualitative Questions:

11. Explain why you decided to volunteer for this experience. Did you get what you had hoped you would get by participating?

12. Did the additional dissection experience enhance your learning \& comprehension of Human Anatomy? Please explain.

Journal of the Scholarship of Teaching and Learning, Vol. 18, No. 3, September 2018.

josotl.indiana.edu 
13. Did the additional dissection experience enhance your understanding of applied anatomy to your $2^{\text {nd }}$ semester coursework? If so, explain how it was beneficial and in which courses did the experience enhance your learning most?

14. Were there any other unexpected advantages to participating in this additional out-of-class time learning experience?

15. Were there any disadvantages to participating in this additional out-of-class time learning experience? If so, please explain.

16. What additional information from the undergraduate program would have been helpful to you during this experience?

17. Is there anything that could have been done to further enhance your learning during this experience?

18. Did you participate in dissecting each region? How did you divide out the responsibilities? Were the responsibilities fairly distributed?

19. How many total days did you spend in the cadaver lab to perform these dissections? How many total hours do you think you spent in the lab performing the dissections?

20. Time spent preparing outside of lab:

a. Did you have to prepare in advance prior to going to the lab to do the dissection?

$$
\text { Yes No }
$$

b. If so, how many hours do you think you spent out of lab preparing?

c. If there was a significant difference in time spent preparing based on the dissection, please indicate accordingly

$\mathrm{UE} \mathrm{/} \mathrm{LE} \mathrm{/} \mathrm{Abdomen}$

21. How many people were in the lab for each dissection? Were there an appropriate number of people participating? Would you have done anything different? Please explain.

22. Knowing what you know now, if you could go back in time, would you still choose to participate in this experience? Why or why not? What would you do different? Would you be interested in also providing a recitation to the undergraduate students as a teaching experience?

23. Did you have access to a cadaver lab when you were an undergraduate?

24. Given your current level of experience, do you believe it would have been beneficial to have had exposure to a cadaver lab during your undergraduate experience?

25. How do you feel having exposure to the cadaver lab when you were an undergraduate would have enhanced your learning and/or preparation for your cadaver experience in graduate school or your decisions regarding graduate school programs, if any

Journal of the Scholarship of Teaching and Learning, Vol. 18, No. 3, September 2018. josotl.indiana.edu 


\section{References}

AAMC-HHMI. (2009). Report of the Scientific Foundations for Future Physicians (SFFP) Committee. Washington, DC. Retrieved from http://www.hhmi.org/grants/pdf/08209_AAMC-HHMI_report.pdfle

Turney, B.W. (2007). Anatomy In a Modern Medical Curricullum. Ann R Coll Surg Engl, 89, 104-107. doi 10.1308/003588407X168244.

Azer, S. A., \& Eizenberg, N. (2007). Do we need dissection in an integrated problem-based learning medical course? Perceptions of first- and second-year students. Surgical and Radiologic Anatomy, 29(2), 173-180. https://doi.org/10.1007/s00276-007-0180-x

Aziz, M. A., Mckenzie, J. C., Wilson, J. S., Cowie, R. J., Ayeni, S. A., \& Dunn, B. K. (2002). The human cadaver in the age of biomedical informatics. Anatomical Record, 269(1), 20-32. https://doi.org/10.1002/ar.10046

Bell, A., \& Mladenovic, R. (2008). The benefits of peer observation of teaching for tutor development. Higher Education, 55(6), 735-752. https://doi.org/10.1007/s10734-007-90931

Bell, M. (2001). Supported reflective practice: a programme of peer observation and feedback for academic teaching development. International Journal for Academic Development, 6(1), 29-39. https://doi.org/10.1080/13601440110033643

Bennett, S., \& Barp, D. (2008). Peer observation - a case for doing it online. Teaching in Higher Education, 13(5), 559-570. https://doi.org/10.1080/13562510802334871

Bergman, E. M., Prince, K. J. A. H., Drukker, J., van der Vleuten, C. P. M., \& Scherpbier, A. J. J. A. (2008). How much anatomy is enough? Anatomical Sciences Education, 1(4), 184-188. https://doi.org/10.1002/ase.35

Bergman, E. M., van der Vleuten, C. P. M., \& Scherpbier, A. J. J. A. (2011). Why don’t they know enough about anatomy? A narrative review. Medical Teacher, 33(5), 403-409. https://doi.org/10.3109/0142159X.2010.536276

Böckers, A., Jerg-Bretzke, L., Lamp, C., Brinkmann, A., Traue, H. C., \& Bö Ckers, T. M. (2010). The gross anatomy course: An analysis of its importance. Anatomical Sciences Education, 3(1), 3-11. https://doi.org/10.1002/ase.124

Brenton, H., Hernandez, J., Bello, F., Strutton, P., Purkayastha, S., Firth, T., \& Darzi, A. (2007). Using multimedia and Web3D to enhance anatomy teaching. Computers and Education, 49(1), 32-53. https://doi.org/10.1016/j.compedu.2005.06.005

Bryk, Anthony S., and Driscoll, M. E. (1988). “The High School as Community: Contextual Influences and Consequences for Students and Teachers.” Madison, Wisconsin: National 
Center on Effective Secondary Schools, Madison, WI.

Byrne, J., Brown, H., \& Challen, D. (2010). Peer development as an alternative to peer observation: a tool to enhance professional development. International Journal for Academic Development, 15(3), 215-228. https://doi.org/10.1080/1360144X.2010.497685

Chan, L. K., \& Cheng, M. M. W. (2011). An analysis of the educational value of lowfidelity anatomy models as external representations. Anatomical Sciences Education, 4(5), 256-263. https://doi.org/10.1002/ase.239

Chapman, S. J., Hakeem, A. R., Marangoni, G., \& Prasad, K. R. (2013). Anatomy in medical education: Perceptions of undergraduate medical students. Annals of Anatomy, 195(5), 409-414. https://doi.org/10.1016/j.aanat.2013.03.005

Craig, S., Tait, N., Boers, D., \& McAndrew, D. (2010). Review of anatomy education in Australian and New Zealand medical schools. ANZ Journal of Surgery, 80(4), 212-216. https://doi.org/10.1111/j.1445-2197.2010.05241.x

Dangerfield, P., Bradley, P., \& Gibbs, T. (2000). Learning gross anatomy in a clinical skills course. Clinical Anatomy, 13(6), 444-447. https://doi.org/10.1002/10982353(2000)13:6<444::AID-CA9>3.0.CO;2-W

Drake, R. L., McBride, J. M., Lachman, N., \& Pawlina, W. (2009). Medical education in the anatomical sciences: The winds of change continue to blow. Anatomical Sciences Education, 2(6), 253-259. https://doi.org/10.1002/ase.117

Dusseau, J., Knutson, D., \& Way, D. (2008). Anatomy correlations: Introducing clinical skills to improve performance in anatomy. Family Medicine, 40(9), 633-637.

Forester, J. P., McWhorter, D. L., \& Cole, M. S. (2002). The relationship between premedical coursework in gross anatomy and histology and medical school performance in gross anatomy and histology. Clinical Anatomy (New York, N.Y.), 15(2), 160-164. https://doi.org/10.1002/ca.1114

Glowacki-Dudka, Michelle; Brown, M. P. (2007). Professional Development Through Faculty Learning Communities. New Horizons in Adult Education and Human Resource Development, 21(1/2).

Gogalniceanu, P., O’Connor, E. F., \& Raftery, A. T. (2009). Undergraduate anatomy teaching in the UK. Bull R Coll Surg Engl. 2009;91(3):102-106.

https://doi.org/10.1308/147363509X407506

Hendry, G. D., \& Oliver, G. R. (2012). Seeing is Believing: The Benefits of Peer Observation. Journal of University Teaching \& Learning Practice, 9(91). http://ro.uow.edu.au/jutlp/vol9/iss1/7 
Johnson, E. O., Charchanti, A. V., \& Troupis, T. G. (2012). Modernization of an anatomy class: From conceptualization to implementation. A case for integrated multimodalmultidisciplinary teaching. Anatomical Sciences Education, 5(6), 354-366. https://doi.org/10.1002/ase.1296

Johnston, A. N. B. (2010). Anatomy for nurses: Providing students with the best learning experience. Nurse Education in Practice, 10(4), 222-226.

https://doi.org/10.1016/j.nepr.2009.11.009

Jones, C. (2009). Interdisciplinary Approach - Advantages, Disadvantages, and the Future Benefits of Interdisciplinary Studies. Essai, 7(2009), 75-81.

Keig, L., and Waggoner, M. D. (1994). Collaborative peer review: The role of faculty in improving college teaching. ERIC Publications.

Kerby, J., Shukur, Z. N., \& Shalhoub, J. (2011). The relationships between learning outcomes and methods of teaching anatomy as perceived by medical students. Clinical Anatomy, 24(4), 489-497. https://doi.org/10.1002/ca.21059

Korf, H. W., Wicht, H., Snipes, R. L., Timmermans, J. P., Paulsen, F., Rune, G., \& Baumgart-Vogt, E. (2008). The dissection course - necessary and indispensable for teaching anatomy to medical students. Annals of Anatomy, 190(1), 16-22. https://doi.org/10.1016/j.aanat.2007.10.001

Krontiris-Litowitz, J. (2008). Using truncated lectures, conceptual exercises, and manipulatives to improve learning in the neuroanatomy classroom. Advances in Physiology Education, 32(2), 152-6. https://doi.org/10.1152/advan.00103.2007

Lujan, H. L., \& DiCarlo, S. E. (2006). First-year medical students prefer multiple learning styles. Advances in Physiology Education, 30(1), 13-16.

https://doi.org/10.1152/advan.00045.2005

McLachlan, J. C., \& Patten, D. (2006). Anatomy teaching: Ghosts of the past, present and future. Medical Education, 40(3), 243-253. https://doi.org/10.1111/j.13652929.2006.02401.x

McNulty, J. A., Sonntag, B., \& Sinacore, J. M. (2009). Evaluation of computer-aided instruction in a gross anatomy course: A six-year study. Anatomical Sciences Education, 2(1), 2-8. https://doi.org/10.1002/ase.66

Miller, S. A., Perrotti, W., Silverthorn, D. U., Dalley, A. F., \& Rarey, K. E. (2002). From college to clinic: reasoning over memorization is key for understanding anatomy. The Anatomical Record, 269(2), 69-80. https://doi.org/10.1002/ar.10071

Papa, V., \& Vaccarezza, M. (2013). Teaching anatomy in the XXI century: New aspects and pitfalls. The Scientific World Journal. https://doi.org/10.1155/2013/310348 
Patel, K. M., \& Moxham, B. J. (2006). Attitudes of professional anatomists to curricular change. Clinical Anatomy. https://doi.org/10.1002/ca.20249

Pereira, J. A., Pleguezuelos, E., Meri, A., Molina-Ros, A., Molina-Tomas, M. C., \& Masdeu, C. (2007). Effectiveness of using blended learning strategies for teaching and learning human anatomy. Medical Education, 41(2), 189-195. https://doi.org/10.1111/j.1365-2929.2006.02672.x

Peterson, C. A., \& Tucker, R. P. (2005). Undergraduate coursework in anatomy as a predictor of performance: Comparison between students taking a medical gross anatomy course of average length and a course shortened by curriculum reform. Clinical Anatomy, 18(7), 540-547. https://doi.org/10.1002/ca.20154

Peterson, D. C., \& Mlynarczyk, G. S. A. (2016). Analysis of traditional versus threedimensional augmented curriculum on anatomical learning outcome measures. Anatomical Sciences Education, 9(6), 529-536. https://doi.org/10.1002/ase.1612

Rolfe, I. E., \& Sanson-Fisher, R. W. (2002). Translating learning principles into practice: A new strategy for learning clinical skills. Medical Education, 36(4), 345-352. https://doi.org/10.1046/j.1365-2923.2002.01170.x

Saltarelli, A. J., Roseth, C. J., \& Saltarelli, W. A. (2014). Cadavers, Multimedia Simulation, and Anatomy Human Cadavers vs. Multimedia Simulation: A Study of Student Learning in Anatomy. Anatomical Sciences Education, 7, 331-339. https://doi.org/10.1002/ase.1429

Shaffer, K. (2004). Teaching anatomy in the digital world. N Engl J Med, 351(13), 127981. https://doi.org/10.1056/NEJMp048100

Sicat, B. L., Kreutzer, K. O. K., Gary, J., Ivey, C. K., Marlowe, E. P., Pellegrini, J. M., ... Simons, D. F. (2014). A collaboration among health sciences schools to enhance faculty development in teaching. American Journal of Pharmaceutical Education, 78(5). https://doi.org/10.5688/ajpe785102

Simpson, J. S. (2014). An Economical Approach to Teaching Cadaver Anatomy: A 10-Year Retrospective. The American Biology Teacher, 76(1), 42-46. https://doi.org/10.1525/abt.2014.76.1.9

Sugand, K., Abrahams, P., \& Khurana, A. (2010). The anatomy of anatomy: a review for its modernization. Anatomical Sciences Education, 3(2), 83-93.

https://doi.org/10.1002/ase.139

Terrell, M. (2006). Anatomy of learning: Instructional design principles for the anatomical sciences. Anatomical Record - Part B New Anatomist. https://doi.org/10.1002/ar.b.20116 